\title{
Influence of Bisphosphonate Drugs on Oral Rehabilitation with Implants
}

\author{
Samili Albuquerque Gurgel', Edilson Martins Rodrigues Neto', Ana Cristina de Mello Fiallos', Camila Costa Dias', \\ Analice Mendes Barreto Fernandes ${ }^{1}$, Joao Hildo de Carvalho Furtado Junior ${ }^{1}$, Celiane Mary Tapety Carneiro ${ }^{1}$, Mônica do Amaral Silva², \\ Guilherme Antonio Lopes de Oliveira², Emmanuel Arraes de Alencar Júnior', Carlos Ricardo de Queiroz Martiniano' \\ 'Pharmacy, Dentistry and Nursering School, Federal University of Ceara, Fortaleza-CE-Brazil. \\ ${ }^{2} \mathrm{~S}$ chool of Pharmacy, Christus Faculty of Piauí, Piaui, BRAZIL.
}

\begin{abstract}
Bisphosphonate (BF) is a drug used to treat some bone pathologies, such as osteoporosis, multiple myeloma, Paget's disease, and to treat bone metastasis. These drugs increase the risk of osteonecrosis, where several factors are considered to be risk factors for this, including surgery for placing dental implants and tooth extraction. The objective of this present study was to conduct a literature review on the emergence of osteonecrosis in patients who are or have used BFand have undergone dental implant surgery. A literature review was carried out using the PUBMED, LILACS, Bireme and Scielo databases. To carry out this research, 24 articles were selected between the years 2008 and 2020, which were related to the topic of the use of BF in dental implantology. There is no clear relationship between BF and osseointegration of dental implants. Studies show that BFs increase the mechanical stability of implants if used locally, but they can also increase the risk of osteonecrosis of the jaw if used systemically. BFs have different effects at bone repair sites and bone remodeling sites. It is known that bone can be formed at the site of repair, but this drug will
\end{abstract}

decrease bone formation to a similar level of bone resorption at the site of remodeling. Despite the risk, implant surgery is not contraindicated in patients undergoing oral treatment. The rate of osteonecrosis related to the use of BF is low, even so the professional must consider the risk and be cautious to prevent this from happening.

Key words: Osseointegration, Dental implants, Bisphosphonates, Osteonecrosis.

Correspondence

Edilson Martins Rodrigues Neto,

Pharmacy Dentistry and Nursering School, Federal University of Ceara, 1210 Capital Francisco Pedro Street, Fortaleza-CE-Brazil, Zip Code 60430372.

Email: edilsonmrneto@hotmail.com

DOI: 10.5530/jyp.2021.13.40

\section{INTRODUCTION}

The use of dental implants increased with the advent of osseointegration. Several patients started to opt for a more lasting and comfortable treatment in comparison to removable prostheses. On the other hand, with the increasing demand for the aesthetic and functional factor, there was a need to study risk factors that interfere with the success on the osseointegration of dental implants. ${ }^{[1,2]}$

Osseointegration can be affected not only by the characteristics of the implant and by the surgical procedure, but by the quality and quantity of bone. ${ }^{[3]}$ Although the survival rate of dental implants in a 10 -year observation is greater than $90 \%$ in total edentulous patients in the mandible, the success of implant rehabilitation is directly related to the patient's bone conditions. Because of this, much has been studied about medications that affect the metabolism of bone tissues. ${ }^{[4]}$

Bisphosphonate $(\mathrm{BF})$ is a drug used to treat some bone pathologies, such as osteoporosis, multiple myeloma, Paget's disease, and to treat bone metastasis ${ }^{[5]}$ It acts on the body by altering the cell cycle of osteoclasts, inducing their apoptosis and inhibiting osteoclastic bone resorption. ${ }^{[6]}$ It can be used orally and intravenously, from the moment when the BF are introduced into bone tissues, they can have a long half-life, as in the case of Alendronate, up to 10 years.

However, despite being considered a drug of first choice in the treatment of some bone diseases, the main complication that can be seen is osteonecrosis of the jaws. ${ }^{[6]}$ It can be understood as an exposure of necrotic bone in the region of the jaws that does not heal during the period of 8 weeks, in patients who use or have used bisphosphonate and who have not received radiotherapy in the maxillofacial region. ${ }^{[7]}$ The first case reported in the literature about this type of necrosis was highlighted in the study by Marx et al. in 2003, in which the appearance of osteonecrosis in cancer patients who used intravenous BF was analyzed. Over the years, the number of publications on the subject increased. ${ }^{[5,8]}$

Several factors are considered to be at risk for the onset of osteonecrosis, among them surgery for placing dental implants and tooth extraction are considered as the main ones. ${ }^{[5,8]}$

Thus, the aim of this study is to review the literature on the onset of osteonecrosis in patients who are or have used bisphosphonate and have undergone dental implant surgery.

\section{MATERIALS AND METHODS}

A literature review was carried out using the PUBMED, LILACS, Bireme and Scielo databases. The descriptors used, osseointegration, dental implants, biphosphonates and osteonecrosis, were duly consulted in the descriptors of the virtual health library, Decs. To carry out this research, 24 articles were selected between the years 2008 and 2020, which were related to the theme of the use of bisphosphonate in implantology.

\section{Bisphosphonates}

Bisphosphonates are compounds analogous to inorganic pyrophosphate, having a high affinity for bone hydroxyapatite. In the past, they were known as diphosphonates, discovered in the 19th century and synthesized on a large scale in Germany in 1865 . Their use began in the textile 
Gurgel, et al.: Bisphosphonate Drugs on Oral Rehabilitation

industry and plumbing to prevent the deposition of calcium carbonate on their internal walls. This served as a basis for the development of modern bisphosphonates, which had an impulse after realizing that the inorganic pyrophosphate of serum and urine were able to inhibit calcium precipitation in vitro. In addition, a few years later it was found that it had a function in uniting with the hydroxyapatite present in the human body, being neutralized in the stomach mucosa. ${ }^{[8]}$

$\mathrm{BF}$ act by producing pharmacological effects on bone tissue, being potent suppressors of bone resorption, they play an important role in skeletal disorders with unbalanced bone remodeling rates. They are effective for the treatment of diseases that affect bone metabolism, characterized by increased resorption, such as osteoporosis, Paget's disease, malignancy hypercalcemia, multiple myeloma and bone metastasis of prostate, lung and breast cancer. This class is divided into first generation without nitrogen (clodronate, etidronate and tiludronate) and second and third generation containing nitrogen (alendronate, risedronate, ibandronate and zoledronate), where the latter differ from the others by adhering more firmly to the hydroxyapatite mineral in the bone. Oral bisphosphonates are poorly absorbed and have less than $1 \%$ bioavailability, while intravenous ones are completely bioavailable. ${ }^{[9,10]}$

These drugs are commonly used to alter bone metabolism, preventing bone loss in diseases such as osteoporosis and bone cancer. The use of BF has been constantly associated with osteonecrosis of the jaws, generating controversies in the debate about rehabilitation. ${ }^{[11]}$

The continuous use of these drugs can cause the emergence of osteonecrosis of the jaws as an adverse effect in up to $4.3 \%$ of patients. It is defined as the presence of exposed, unhealed bone in the maxilla or mandible, for a period greater than eight weeks, in patients who took systemic bisphosphonates, but who did not receive localized radiation therapy. ${ }^{[12]}$

Osteoporosis, for example, is a progressive systemic disease of the skeleton characterized by low bone mass and deterioration of bone tissue, with the consequent increase in bone fragility and susceptibility to fracture. The most common treatment for osteoporosis involves the use of BF, as they act by inhibiting the activity of osteoclasts, preventing bone resorption and reducing their turnover. The most commonly prescribed BF is oral alendronate. Intravenous prescription is used in patients with cancer and bone metastases to prevent bone complications and to treat tumorinduced hypercalcemia. ${ }^{[13]}$ Currently in therapy, several drugs are available with varied routes of administration and therapeutic applications, as shown in Tables 1 and $2 .^{[10,14]}$

\section{Osteonecrosis}

The first case of painful bone exposure in the jaws of patients who received pamidronate and zoledronate was reported in 2003. After that, dental surgeons were concerned about studying bisphosphonateinduced osteonecrosis of the jaws. Bisphosphonate-induced osteonecrosis of the jaws is reported as the presence of unhealed exposed bone in the jaws, which may persist for more than eight weeks in patients who have been treated with systemic bisphosphonates, but who have not received localized radiation therapy. This condition affects the quality of life and produces morbidity in patients. ${ }^{[15]}$

Table 1: Commercialized bisphosphonates, Freitas et al. ${ }^{[10]}$

\begin{tabular}{ccc}
\hline $\begin{array}{c}\text { Oral } \\
\text { Bisphosphonates }\end{array}$ & $\begin{array}{c}\text { Intravenous } \\
\text { Bisphosphonates }\end{array}$ & $\begin{array}{c}\text { Oral / Intravenous } \\
\text { Bisphosphonates }\end{array}$ \\
\hline Alendronate & Zolendronate & Clodronate \\
Risedronato & Pamidronato & Ibandronate \\
Etidronate & & \\
Tiludronate & & \\
\hline
\end{tabular}

Table 2: Bisphosphonates marketed and their indications, Tellez et al. ${ }^{[14]}$

\begin{tabular}{cccc}
\hline MEDICATION & VIA & RECOMMENDATION & DOSAGE \\
\hline $\begin{array}{c}\text { Etidronato } \\
\text { (Didronel) }\end{array}$ & Oral & Paget's disease & $\begin{array}{c}300-750 \mathrm{mg} / \text { day - } \\
6 \mathrm{months}\end{array}$ \\
$\begin{array}{c}\text { Tiludronato } \\
\text { (Skelid) }\end{array}$ & Oral & Paget's disease & $\begin{array}{c}400 \mathrm{mg} / \text { day - } \\
4 \mathrm{months}\end{array}$ \\
$\begin{array}{c}\text { Alendronato } \\
\text { (Fosamax) }\end{array}$ & Oral & Osteoporosis & $10 \mathrm{mg} /$ day - 1 week \\
$\begin{array}{c}\text { Resindronato } \\
\text { (Actonel) }\end{array}$ & Oral & Osteoporosis & $5 \mathrm{mg} /$ day - 1 week \\
$\begin{array}{c}\text { Ibandronato } \\
\text { (Boniva) }\end{array}$ & Oral & Osteoporosis & $2,5 \mathrm{mg} /$ day - \\
$\begin{array}{c}\text { Pamindronato } \\
\text { (Aredia) }\end{array}$ & Intravenous & Bone metastasis & $90 \mathrm{mg} /$ day - 3 weeks \\
$\begin{array}{c}\text { Zolendronato } \\
\text { (Zometa) }\end{array}$ & Intravenous & Bone metastasis & $3 \mathrm{mg} /$ day - 3 weeks \\
\hline
\end{tabular}

Jaw bones have a higher blood supply than other bones and a faster bone turnover rate, this is related to their daily activity and the presence of teeth, which is why they are large concentrators of bisphosphonates in their structure. In addition, the jaws when subjected to invasive and rehabilitative procedures, end up predisposing the oral structures to bone exposures, this favors microbial contamination and the onset of infections. Thus, the BF in the osteonecrosis process seems to be associated with the cessation of bone remodeling and renewal through the effect of inhibiting osteoclasts by these drugs. Bone cells, osteoblasts and osteocytes live for about 150 days. If after the death of osteoblasts, the mineral matrix is not reabsorbed by osteoclasts, which release bone morphogenetic protein cytokines and growth factors to induce new osteoblasts, osteons become acellular and necrotic. Thus, the small capillaries within the bone become avascular, leading to a failure in the healing process. ${ }^{[15,16]}$

Thus, BF compounds have a high affinity for bone tissue, especially in areas that are remodeling, accumulating for long periods of time in the bone mineral matrix. Depending on the duration of treatment, BP can remain for years. ${ }^{[3]}$

Osteonecrosis of the jaws has been described in patients using bisphosphonates after oral surgery, including the placement of dental implants. This complication depends on the strength and half-life of the medication. Oral use of alendronate, for example, can produce bone exposure after 3 years. An important test is the terminal serum test of type I crossed telopeptide (CTX), which measures the rate of bone turnover. If this value is $\geq 150 \mathrm{pg}$ / $\mathrm{mL}$, the risk of suffering osteonecrosis is zero or minimal, when the values are $<100 \mathrm{pg} / \mathrm{mL}$, the risk of osteonecrosis is increased. ${ }^{[5,17]}$

\section{Implants / Osseointegration in Patients Using Bisphosphonates}

Nowadays, rehabilitation with dental implants is more and more common. They are the best alternative in the quest to improve chewing efficiency, physical and aesthetic health, in addition to having high survival rates. The good clinical performance of dental implants has been attributed to osseointegration. Despite the high success rates, dental implants often fail due to inadequate diagnosis and treatment. ${ }^{[4]}$

Osseointegration is defined as a direct, structural and functional connection between live, mature, organized bone and the surface of an endosseous implant subjected to a functional load for a long period of time. ${ }^{[8]}$

Under normal conditions, bone tissue undergoes continuous remodeling, which depends on the balance between the activities of highly specialized bone cells, osteoblasts and osteoclasts. The use of BF affects the physiology of this process. Since osseointegration strongly depends on bone remod- 
eling and the behavior of osteoblasts and osteoclasts, it is estimated that the action of $\mathrm{BF}$ in this process can have an effect in the initial phase, preventing osseointegration, or even later, delaying healing and causing a loss of integration. ${ }^{[11,18]}$

Among the most serious complications, although infrequent, is osteonecrosis of the jaws related to bisphosphonates. There are great challenges regarding the management of these patients. The results of studies show that there is a great need for further research in the area. ${ }^{[13,15]}$

Even with lower potency than bisphosphonates administered intravenously, the effects of etendronate on implant success have been controversial. Some studies report a significant relationship between its use and implant failure. It is important to note that, due to the increase in life expectancy of human beings, consequently the period of medication and total dosage is longer. ${ }^{[17]}$

There is no clear relationship between BF and osseointegration of dental implants. BFs are known to increase the mechanical stability of implants if used locally while at the same time, they increase the risk of osteonecrosis of the jaw if used systemically. BFs have different effects at bone repair sites and bone remodeling sites. It is known that bone can be formed at the site of repair, but this drug will decrease bone formation to a similar level of bone resorption at the site of remodeling. Therefore, the reverse torque values of the fixation pins are increased in patients receiving this medication. ${ }^{[19]}$

\section{TREATMENT}

The treatment of osteonecrosis associated with BFs is quite complicated, so prevention should be focused, and the elimination of oral infectious conditions before therapy with bisphosphonates has been initiated, in order to minimize oral damage after using these drugs. ${ }^{[20]}$

Thus, treating osteonecrosis is something controversial and challenging, where conduct varies widely among professionals and no effective treatment has been standardized to date. The protocol is directed to each case and depends on the clinical level of the disease. Treatment involves the use of antibiotics, local irrigation with antimicrobial solution, local wound debridement, surgery, use of platelet-rich plasma and hyperbaric oxygenation. ${ }^{[20,21]}$

Patients with asymptomatic bone exposures can be treated with irrigation with antimicrobial solutions, such as chlorhexidine, and have clinical and radiographic follow-up, and with the prescription of systemic antibiotics, such as penicillin or clindamycin. In symptomatic cases, removal of the necrotic bone is indicated, with the least possible tissue damage to both the bone and the adjacent soft tissue. In addition, constant irrigation with antimicrobial solution and maintenance of oral antibiotic therapy may be the treatment of choice. Surgical treatment was mostly inefficient and often exacerbated bone exposure. For patients with drainage in the sinus region and extensive areas of bone exposure, more extensive surgical procedures may be necessary. Patients in situations of drainage of purulent secretion, culture and antibiogram should be performed. In some patients, complete healing may never occur, with a certain level of bone exposure. In addition, some studies have demonstrated the effectiveness of using cell mediators, such as platelet-rich plasma (PRP) associated with surgical debridement, prolonged antibiotic therapy, irrigation with antimicrobials, and clinical and radiographic control for the treatment of avascular osteonecrosis of the jaws. ${ }^{[22,23]}$

\section{PROTOCOLS}

In 2007, the American Association of Maxillofacial and Oral Surgeons (AAOMS) published some guidelines for guiding health professionals, warning about the persistence of necrotic lesions for more than 8 weeks, with no previous history of radiotherapy in the jaw region and report of treatment of the patient, interrupted or current, with bisphosphonates. These guidelines are a set of preventive measures, given the complications caused in the maxillofacial complex by therapy with bisphosphonates. ${ }^{[3]}$

According to these guidelines, it is suggested that patients who will undergo rehabilitation with osseointegrated implants should be instructed to perform routine examinations in the oral cavity and to perform non-invasive emergency treatments in advance; stability of any oral condition; avoid trauma or invasive procedures before starting bisphosphonate therapy; avoid invasive procedures such as implant placement, if necessary, discontinue 3 months before the intervention and 3 months afterwards with the consent of the doctor who prescribes drug therapy and use prostheses on implants adapted and repackaged to avoid trauma. In 2009, the American Association of Maxillofacial and Oral Surgeons modified the classification stage of patients affected by osteonecrosis and proposed treatment strategies. These authors report that osteonecrosis has extraction and iatrogenic trauma as the most common triggering factors, and not mainly due to infections. It is known that the lack of capacity of hypodynamic and hypovascularized bone to compensate for the need for bone remodeling and repair resulting from physiological stress (chewing), iatrogenic trauma (poorly adapted prosthesis), surgical procedures (implant placement) or infections of dental origin have contributed to its appearance as local factors. ${ }^{[3]}$

Oral BFs differ in 3 ways from those administered intravenously. Regarding the period, it needs to have more exposure time to cause osteonecrosis, the amount of bone exposed is less and the symptoms are less severe and the discontinuation of oral bisphosphonate can lead to gradual improvement. Dental implant surgery is contraindicated for patients treated with intravenous bisphosphonates, according to the guidelines of the American Association of Oral and Maxillofacial Surgeons. ${ }^{[19]}$

The lack of consensual treatments with scientific evidence, the lack of emphasis on understanding the pathophysiological mechanisms and the neglect in the adoption of clinical care make osteonecrosis of the jaws a serious public health problem, as medical prescriptions are growing every day. of them in patients with osteoporosis. ${ }^{[3]}$

It is important to inform the patient about the importance of periodic review and instructions on oral hygiene procedures to ensure dental and periodontal health. Prior to any type of surgery, the start of treatment with BF should be as late as possible until the wound is completely healed. Osteoporosis patients who have already started oral treatment with $\mathrm{BF}$ are not at risk for dental intervention in the first three months. Non-invasive dental treatments, such as restorations and endodontics can be performed without specific measures. Patients under oral treatment for less than 3 years have a lower risk of osteonecrosis when undergoing surgery. Most cases of osteonecrosis in these cases are found in patients treated for more than 10 years. Prior to implant surgery, antibiotic prophylaxis with penicillin or metronidazole should be performed beforehand in combination with a quinolone (in case of allergy to penicillin). Clindamycin alone is not recommended because it is ineffective against some species of bacteria. In addition, mouthwashes with $0.12 \%$ chlorhexidine are also recommended twice a day for 2 weeks. The interruption of treatment with bisphosphonates orally, in a period of two to three months before the intervention and until the end of osseointegration, depends on the opinion of the professional who prescribes it, and the benefit/risk for the discontinuation of the medication should always be considered. . It is believed that withdrawal of the drug is not an effective measure, as the drug is kept in the bone for years. When possible, consideration should be given to the examination that checks the level of collagen type I carboxy-terminal telopeptide (CTX) in the blood, as this telopeptide is separated from the collagen molecule by 
osteoclasts during bone resorption, and its level in the blood. it would be proportional to the degree of reabsorption because osteoclastic activity, which would predict osteonecrosis. ${ }^{[3,24]}$

Although some treatments are effective, in the case of osteonecrosis, prevention is always the best option. It is important to emphasize that osteonecrosis due to BF administered orally has less frequency and severity, in addition to responding better to treatment. ${ }^{[20]}$

\section{DISCUSSION}

Rehabilitation with dental implants induces a series of metabolic changes around them. If the bone surrounding the implant has a medium to high concentration of bisphosphonates, these remodeling processes will be prevented. So, it is essential that before starting treatment with bisphosphonates, all dental procedures necessary for proper oral hygiene must be performed. ${ }^{[9]}$

The studied literature points out that in patients treated with intravenous $\mathrm{BF}$, any type of oral invasive procedure, including dental implants, should be avoided. Regarding oral treatment, the literature offers little information about the influence of oral BF on bone repair. However, healthcare professionals should be aware of the risk of osteonecrosis. ${ }^{[9]}$

Ata-Ali et al., 2014 ${ }^{[13]}$ conducted a systematic review and meta-analysis to assess whether bisphosphonate therapy can decrease the success rate of dental implants. A total of eight studies (six retrospective and two prospective) were included in the meta-analysis, with a total of 1288 patients (386 cases and 902 controls) and 4,562 dental implants (1090 dental implants in the cases and 3472 in the controls). This study indicated that there is insufficient evidence that BFs have a negative impact on implant survival.

Matsuo et al., 2015 $5^{[16]}$ assessed the status of dental implants in patients who received intravenous bisphosphonates in a breast cancer cohort study to elucidate the risk of osteonecrosis at the implant site. Among 44 breast cancer patients, a total of 6 had dental implants, teeth only one had osteonecrosis at the implant site. Although a case has been identified, dental implants that were inserted before the administration of intravenous therapy were not a risk factor for the development of osteonecrosis. Freitas et al., 2016 ${ }^{[10]}$ analyzed, through systematic review, patients submitted to bisphosphonate therapy and who received dental implants before, during or after bisphosphonate treatment, comparing them to healthy patients. The study looked at the increase in failure and loss of implant osteonecrosis related to mandible bisphosphonates. Fifteen studies were included, eight retrospective, one prospective and six cases, with a total of 1339 patients analyzed, 3748 implants placed, 152 implant losses and 78 cases of osteonecrosis.

Madrid and Sanz (2009) ${ }^{[6]}$ studied the impact that oral bisphosphonates had on implant therapy. The authors concluded that bisphosphonates did not change the implant survival rate for a period of 4 years. The authors suggest that the placement of an implant can be considered a safe procedure in patients using BF for a period of 5 years in relation to the occurrence of osteonecrosis.

It is noticed that the use of bisphosphonates is becoming more and more widespread, given the increase in life expectancy and the population that uses them. Studies to evaluate the risk factors for maxillary osteonecrosis in patients after rehabilitation with dental implants receiving treatment with oral bisphosphonates are scarce and it is necessary to perform them. In addition, success in implanted restorations requires adequate assessment of risk factors, with the correct indication for the patient. ${ }^{[9]}$

\section{CONCLUSION}

The success of implant rehabilitation is directly related to the patient's general health, where each case must be evaluated individually. Due to the flaws in the therapies proposed for the treatment of osteonecrosis of the jaws, it is believed that prevention should be the focus in patients who use bisphosphonates. Despite the risk, implant surgery is not contraindicated in patients undergoing oral treatment, however it should be avoided in patients undergoing intravenous therapy. The rate of osteonecrosis related to the use of BF is low, even so the professional must consider the risk and be cautious to prevent this from happening. It is important that the dentist has the pharmacological knowledge, mechanism, pharmacokinetics and pharmacodynamics of these drugs. In addition, as a precaution it is important that patients sign the term consent with explanations about this risk.

\section{REFERENCES}

1. Marques LARV, da Costa Júnior EA, Lotif MAL, Neto EMR, da Silva FFC, de Queiroz Martiniano CR. Application of BMP-2 for bone graft in Dentistry. RSBO Rev Sul-Bras Odontol. 2015;12(1):88-93.

2. Lotif MAL, Marques LARV, Neto EM, Dantas TS, Martiniano CRQ. O uso do plasma rico em plaquetas para correção de defeitos ósseos maxilares em Implantodontia. Full Dent Sci. 2018;9(34):62-7. doi: 10.24077/2018;934-6267.

3. Mellado-Valero A, Ferrer-García JC, Calvo-Catalá J, Labaig-Rueda C. Implant treatment in patients with osteoporosis. Med Oral Patol Oral Cir Bucal. 2010;15(1):e52-7. doi: 10.4317/medoral.15.e52, PMID 19767691.

4. Alghamdi HS. Methods to improve osseointegration of dental implants in low quality (Type-IV) bone: an overview. J Funct Biomater. 2018;9(1):7. doi: 10.3390/ jfb9010007, PMID 29342830.

5. Flichy-Fernández AJ, Balaguer-Martínez J, Peñarrocha-Diago M, Bagán JV. Bisphosphonates and dental implants: current problems. Med Oral Patol Oral Cir Bucal. 2009;14(7):E355-60. PMID 19561566.

6. Madrid C, Sanz M. What impact do systemically administrated bisphosphonates have on oral implant therapy? A systematic review. Clin Oral Implants Res. 2009;20;Suppl 4:87-95. doi: 10.1111/j.1600-0501.2009.01772.x, PMID 19663954.

7. Bedogni A, Bettini G, Totola A, Saia G, Nocini PF. Oral bisphosphonate-associated osteonecrosis of the jaw after implant surgery: a case report and literature review. J Oral Maxillofac Surg. 2010;68(7):1662-6. doi: 10.1016/j. joms.2010.02.037, PMID 20561470.

8. Bispo LB. Considerações da Implantologia sobre a osteonecrose dos maxilares potencializada pela terapia com bisfosfonatos. Rev Bras Odontol. 2014; 70(2):196-201.

9. Serra MP, Llorca CS, Donat FJ. Oral implants in patients receiving bisphosphonates: a review and update. Med Oral Patol Oral Cir Bucal. 2008;13(12):E755-60. PMID 19047961.

10. de-Freitas NR, Lima LB, de-Moura MB, Veloso-Guedes CC, Simamoto-Júnior PC de-Magalhães D. Bisphosphonate treatment and dental implants: A systematic review. Med Oral Patol Oral Cir Bucal. 2016;21(5):e644-51. doi: 10.4317/medoral.20920, PMID 27475681.

11. Thirunavukarasu A, Pinto HG, Seymour KG. Bisphosphonate and implant dentistry - is it safe? Prim Dent J. 2015;4(3):30-3. doi: 10.1308/ 205016815815944650, PMID 26556516

12. Alves LMN, da Costa Hidalgo LR, da Conceição LS, Oliveira GM, de Freitas Borges KR, Passos WG. Complicações em Implantodontia: revisão de literatura. J Orofac Investig. 2017;4(1):20-9.

13. Ata-Ali J, Ata-Ali F, Peñarrocha-Oltra D, Galindo-Moreno P. What is the impact of bisphosphonate therapy upon dental implant survival? A systematic review and meta-analysis. Clin Oral Implants Res. 2016;27(2):e38-46. doi: 10.1111/ clr.12526, PMID 25406770.

14. Telles D, Hollweg H, Castellucci L, Lourenço EJV. Planejamento das reabilitações protéticas nos pacientes edentados. Prótese total-convencional e sobre implantes. Vol. $1^{\text {a }}$ ed. São Paulo: Santos; 2004.

15. Santos LCS, Pereira RP, Gusmão JMR, Almeida ODSd. Influência do uso de bisfosfonatos em pacientes submetidos a implantes dentários: revisão de literatura. J Dent Pub H. 2016;7(1):22-30. doi: 10.17267/2596-3368dentistry. v7i1.706.

16. Matsuo A, Hamada $H$, Takahashi $H$, Okamoto A, Kaise $H$, Chikazu D. Evaluation of dental implants as a risk factor for the development of bisphosphonaterelated osteonecrosis of the jaw in breast cancer patients. Odontology. 2016;104(3):363-71. doi: 10.1007/s10266-015-0207-4, PMID 25956267.

17. ZushiY, Takaoka K, Tamaoka J, Ueta M, Noguchi K, Kishimoto H. Treatment with teriparatide for advanced bisphosphonate-related osteonecrosis of the jaw around dental implants: a case report. Int J Implant Dent. 2017;3(1):11. doi: 10.1186/s40729-017-0074-6, PMID 28361376.

18. Araújo-Gomes N, Romero-Gavilán F, García-Arnáez I, Martínez-Ramos C, Sánchez-Pérez AM, Azkargorta M, Elortza F, de Llano JJM, Gurruchaga M, Goñi I, Suay J. Osseointegration mechanisms: a proteomic approach. J Biol Inorg Chem. 2018;23(3):459-70. doi: 10.1007/s00775-018-1553-9, PMID 
29572572.

19. Qamheya AHA, Yeniyol S, Arisan V. Bisphosphonate-related osteonecrosis of the jaw and dental implants. J Istanb Univ Fac Dent. 2016;50(1):59-64. doi: 10.17096/jiufd.24812, PMID 28955557.

20. Brozoski MA, Traina AA, Deboni MC, Marques MM, Naclério-Homem Mda G. Bisphosphonate-related osteonecrosis of the jaw. Rev Bras Reumatol. 2012;52(2):265-70. doi: 10.1590/S0482-50042012000200010, PMID 22460415.

21. Anitua $E$, Begoña $L$, Orive $G$. Treatment of hemimandibular paresthesia in a patient with bisphosphonate-related osteonecrosis of the jaw (BRONJ) by combining surgical resection and PRGF-Endoret. $\mathrm{Br} J$ Oral Maxillofac Surg. 2013;51(8):e272-4. doi: 10.1016/.j.bjoms.2012.08.018, PMID 23201057.
22. Endo $Y$, Funayama $H$, Yamaguchi $K$, Monma $Y$, Yu Z, Deng $X$, Oizumi T, Shikama $Y$, Tanaka Y, Okada S, Kim S, Kiyama T, Bando K, Shima K, Suzuki H, Takahashi T. [Basic studies on the mechanism, prevention, and treatment of osteonecrosis of the jaw induced by bisphosphonates]. Yakugaku Zasshi. 2020;140(1):63-79. doi: 10.1248/yakushi.19-00125, PMID 31902887.

23. Lopes I, Zenha H, Costa H, Barroso J. Osteonecrose da mandíbula associada ao uso de bifosfonatos: uma patologia secundária grave. Arq Med. 2009;23(5):181-5.

24. Assael LA. Oral bisphosphonates as a cause of bisphosphonate-related osteonecrosis of the jaws: clinical findings, assessment of risks, and preventive strategies. J Oral Maxillofac Surg. 2009;67(5);Suppl:35-43. doi: 10.1016/ן. joms.2009.01.003, PMID 19371813.

Article History: Submission Date : 18-04-2021; Revised Date : 02-05-2021; Acceptance Date : 03-06-2021.

Cite this article: Gurgel SA, Neto EMR, Fiallos ACM, Dias CC, Fernandes AMB, Junior JHCF, Carneiro CMT, Silva MA, Oliveira GAL, Martiniano CRO. Influence of Bisphosphonate Drugs on Oral Rehabilitation with Implants. J Young Pharm. 2021;13(3):192-6. 